\title{
Olivine-Control Trends: A Mauna Loa Perspective
}

\author{
J. MiCHAEL RHODES ${ }^{1 *}$ \\ ${ }^{1}$ University Massachusetts, Amherst, MA 01003,USA \\ (*correspondence: jmrhodes@geo.umass.edu)
}

Linear correlations between major and trace elements, modal olivine and $\mathrm{MgO}$ are commonly referred to as "Olivine-Control Trends. These trends are characteristic of Hawaiian tholeiites in general, and Mauna Loa volcano in particular. The trends are attributed to the combined effects of the processes of olivine crystal fractionation and accumulation into picritic $(>12 \% \mathrm{MgO})$ magmas. The Mauna Loa data range from $\sim 7$ to 33 wt. $\% \mathrm{MgO}, 0$ to 48 modal $\%$ olivine and include sub-aerial and sub-marine lavas. The age range is around $600 \mathrm{ka}$, over half the inferred life-history of the volcano and encompass a wide isotopic range. These linear trends are, however, not the simple results of olivine fractionation and accumulation, but are, instead, mixing trends between an olivine cargo scavenged from prior eruptions and basaltic magmas with around $7 \% \mathrm{MgO}$. These are multiplysaturated magmas, perched at the end of the olivine-control trend, the result of "steadystate" replenishment of a magma reservoir. Co-existing glass, whole-rock and olivine data show that a third, picritic melt component is required to account for the whole-rock linear trends. The typical olivines in these lavas (Fo87-91) crystallized from picritic melts with $\mathrm{MgO}>12-18 \%$. These picritic melts are shown to lie close to the linear whole-rock trends. Such a melt is the obvious source of the forsteritic olivines, and is an appropriate parental magma for the evolved end-member of the mixing trends. 